Marquette University

e-Publications@Marquette

Psychology Faculty Research and Publications

Psychology, Department of

$1-1-2005$

\title{
Relationship Factors in Treating Substance Use Disorders
}

Jay L. Lebow

The Family Institute at Northwestern University

John Kelly

Brown University

Lynne M. Knobloch-Fedders

Marquette University, lynne.knobloch-fedders@marquette.edu

RudolfMoos

Stanford University

Published version. "Relationship Factors in Treating Substance Abuse Disorders," in Principles of Therapeutic Change that Work, edited by Louis G. Castonguay and Larry E. Beutler. New York : Oxford University Press, 2006: 293-317. Publisher link. @ 2006 Oxford University Press. Used with permission. 


\title{
Relationship Factors in Treating Substance Use Disorders
}

\author{
Jay Lebow \\ John Kelly \\ Lynne M. Knobloch-Fedders \\ Rudolf Moos
}

\section{INTRODUCTION}

Research assessing treatments for substance use disorders has primarily focused on the impact of treatments on outcome. As in most of the substantive literatures assessing the efficacy of treatments for specific disorders, the links between process and outcome have rarely assumed a central focus. Primarily, the study of the impact of relationship factors on outcome has occurred in the context of research with heterogeneous groupings of clients who manifest a wide array of diagnoses (Norcross, 2002a). Nonetheless, our review points to a number of emerging principles concerned with the importance of relationship factors in influencing client outcomes in treatments of the substance use disorders.

In this chapter, we survey the literatures connecting several types of relationship factors and several specific domains of substance use disorders. Because of the commonalities in the role of relationship factors in substance use and eating disorders, we also include studies that have focused on eating disorders. These are literatures often reviewed without regard to one another. In the research we survey, we include studies examining treatments for alcohol, drug abuse, smoking, and eating related problems. We focus on relationship factors that assess the connection between therapist and client, the connection between family and client, and the connection between peers and client. As in the other chapters in this volume, we limit our scope to treatments of adult clients, excluding the considerable literature on adolescent substance use and eating disorders.

To identify relevant findings, we first examined studies that contributed to the formulation of empirically supported principles of treatment, as compiled in specific reviews of this area (Chambless \& Hollon, 1998; Nathan \& Gorman, 2002). The primary focus of these reviews was to identify treatments that were empirically associated with beneficial outcomes. In general, the studies covered in these reviews did not focus on the therapist-patient relationship, relationships with. family or peers, or on within-treatment therapeu- 
tic processes. Accordingly, we extended our net beyond the studies summarized in these reviews. We thought that the quality of relationships could affect the process and outcome of treatments other than those shown to be efficacious in controlled treatment trials. Moreover, relationship factors can influence the process and outcome of nonspecific comparison or "placebo" treatment conditions. Accordingly, we broadened our search for relevant articles.

We searched the literature in PsychINFO ${ }^{\mathrm{TM}}$ and Medline $^{\mathrm{TM}}$ as well as in the reference lists of relevant articles. We undertook an additional search in a database of more than 5,000 studies on the treatment of alcohol abuse/dependence, and in a further database containing 990 articles on the treatment of other drug abuse/dependence compiled as part of an ongoing effort to examine substance use disorder treatment (e.g., Moyer, Finney, \& Swearingen, 2002; Moyer, Finney, Swearingen, \& Vergun, 2002), and similar bodies of published research examining smoking and eating disorder. Search terms used included: alliance, therapeutic alliance, therapeutic relationship, working alliance, helping alliance, empathy, self-disclosure, rapport, positive regard, genuineness, couple, and family.

\section{THE THERAPIST-CLIENT RELATIONSHIP}

Interest in the idea that the quality of interpersonal relationships can help ameliorate mental illness emerged with the rise of moral treatment and the York Retreat almost 200 years ago (Tuke, 1813). Building on this idea, Freud (1912) thought that some mental disorders could be treated by verbal dialogue within the context of a professional relationship. More recently, Rogers (1957) asserted that the therapist's ability to be empathic, genuine, and accepting of the client was a necessary and sufficient condition for positive personal change. In the last four decades, a large body of research has demonstrated that clients of therapists who are more empathic and genuine, and who experience a supportive bond with the therapist, have better outcomes (Horvath \& Symonds, 1991; Martin, Garske, \& Davis, 2000; Norcross, 2002b; Truax \& Carkhuff, 1967).
Broadly defined, the therapeutic alliance is the collaborative relationship between client and therapist; it reflects their emotional bond, the therapist's empathy for the client, and a shared presumption about the tasks and goals of treatment (Hatcher \& Barends, 1996). Other terms, such as "working alliance" and "helping alliance," have also been used to refer to specific aspects of the therapist-client relationship. "Working alliance" focuses on the client's capacity to actively engage in treatment (Greenson, 1965), whereas "helping alliance" refers to the client's experience of the therapeutic relationship and treatment as helpful (Luborsky et al., 1996). Although these conceptual distinctions may be useful, we use the more general term "therapeutic alliance" to reflect this broad domain.

Division 29's Task Force on Empirically Supported Psychotherapy Relationships (Norcross, 2002a) reviewed two decades of empirical research that consistently demonstrates that the quality of the therapeutic alliance between therapist and client affects outcome. The magnitude of this association seems to remain constant across such variables as the type of psychotherapy, whether the outcome is assessed from the perspective of the therapist, client, or outside observer; and when in therapy the alliance is measured (Horvath \& Bedi, 2002). However, despite the fact that substance use disorders are the most prevalent DSM-IV (American Psychiatric Association, 1994) Axis I diagnoses, there is a relative lack of information about treatment alliance in the substance use disorders literature. In part, this is because substance use disorders have only recently been accepted as primary or independent conditions. When these disorders are viewed as secondary to other psychopathology, therapeutic attention typically is focused on the presumed underlying problem rather than on the substance use disorder. In addition, because counselors with relatively little formal psychotherapy training often treat substance use disorders, these disorders have not been a primary focus in training programs or standard clinical practice (Miller \& Brown, 1997). Most strikingly, the therapeutic alliance has rarely been investigated in the context of intervention for smoking cessation and obesity treatment, possibly because these treatments rely heavily on didactic, self-help, or group intervention formats. 
As is the case with other disorders (Luborsky et al., 2002; Wampold et al., 1997), robust differences do not emerge in outcome between seemingly disparate therapeutic ideologies and practices in the substance use disorder field. However, therapists' success rates vary substantially. For example, among opiate-dependent outpatients assigned to supportive-expressive psychotherapy or cognitive-behavioral psychotherapy, variations in outcome among clients of different therapists were larger than variations in outcome between the two treatments (Luborsky, Crits-Christoph, McLellan, et al., 1986). Such findings support the search for common dimensions of different treatments.

Here we review the literature on therapistclient relationship factors in the treatment of substance use disorders, consider the determinants of these factors, examine how these factors influence the process and outcome of treatment, and formulate principles of effective treatment.

We believe that the alliance emerges from the interaction between the therapist and client, and is not due primarily to individual characteristics of either person. For example, therapists may vary widely in their empathy depending on the client with whom they are working, and clients may vary widely in their problem expression depending on the therapist with whom they are working (Moos \& MacIntosh, 1970). Because of these interactional factors, the quality of the therapist-patient relationship could affect the process and outcome of treatments in ways that are not readily apparent in research that does not attend to such interactions of client and therapist.

\section{Assessing the Therapist-Client Relationship}

Studies in this area have used diverse measures of therapist empathy and helping alliance, including mainly (1) the Barrett-Lennard Relationship Inventory (BLRI; Barrett-Lennard, 1962), which measures aspects of interpersonal behavior that reflect Rogers's (1957) ideas about the conditions necessary for therapeutic change; (2) the Helping Alliance Questionnaire, which is part of the Penn Helping Alliance Scales (HAQ; Alexander \& Luborsky, 1986; Luborsky et al., 1996); (3) the Working Alliance Inventory (WAI; Horvath \& Greenberg, 1989); (4) the California Psychother- apy Alliance Scale (CALPAS; Gaston \& Marmar, 1994); and (5) the Vanderbilt Therapeutic Alliance Scale (VTAS; Hartley \& Strupp, 1983).

The original HAQ was composed of 11 items rated on four-point scales varying from completely disagree, disagree, agree, to completely agree. It measured perceived helpfulness, or the patient's experience that the therapist is helpful (e.g., "I believe that my therapist is helping me"), and collaboration or bonding, or the patient's experience of working jointly with the therapist toward treatment goals (e.g., "I feel that I am working together with the therapist in a joint effort").

The revised HAQ-II is composed of 19 items rated on 6-point Likert scales (varying from "strongly not true" to "strongly true") that are summed to create a total alliance score. Patients and therapists complete parallel versions of the measure. Internal consistency and stability of the HAQ-II are moderate to high and there is good convergent validity with the CALPAS. Agreement between patients' and therapists' assessments of the therapeutic relationship varies from lowmoderate to relatively high (Belding et al., 1997; Luborsky et al., 1996; Petry \& Bickel, 1999).

The WAI is composed of 36-items rated on 7point Likert scales (varying from never to always) that tap three dimensions reflecting the goals and tasks of therapy, and the bond between the patient and therapist. The WAI has parallel forms for the patient's and the therapist's ratings, and has wellestablished internal consistency, interrater reliability, and construct validity (Horvath \& Greenberg, 1989; Safran \& Wallner, 1991; Tracey \& Kokotovic, 1989). The three WAI subscales tend to be highly correlated and, thus, the overall score is typically used to measure one general alliance dimension (Connors et al., 2000).

The CALPAS consists of 24 items grouped into four subscales that tap the patients' commitment to treatment and ability to explore problems in treatment, patient-therapist agreement on treatment procedures and goals, and therapist involvement and understanding. The CALPAS can be completed by the therapist or the patient and has high internal consistency (Gaston \& Marmar, 1994; Luborsky et al., 1996; Marmar et al., 1989).

The VTAS is composed of 18 items that tap the therapist's contributions to the alliance, 14 items that assess the patient's contributions, and 
12 items that focus on patient-therapist interactions or mutuality. The VTAS items are rated from interview transcripts or videotapes and interrater reliability and internal consistency of the Scale is moderate to high (Hartley \& Strupp, 1983). There also is the Vanderbilt Negative Indicators Scale (VNIS), which focuses on aspects of the therapistclient relationship that could lead to negative consequences of treatment.

Other measures used to assess alliance in substance use disorder treatment include the Client Evaluation of the Counselor Form, which is composed of ten 5-point scale items on which clients rate their counselor on rapport, trust, and expertness. The items are summed to yield an overall score that reflects counselor respect (Simpson, Joe, Rowan-Szal, \& Greener, 1995). There also is the Counselor Evaluation of Client Form, on which counselors rate their client on rapport, motivation, and self-confidence (Simpson et al., 1995). Finally, one study used the Client Experiences and Satisfaction Questionnaire, on which clients assess their relationship with a counselor and how well the counselor treated and understood them (Hyams, Cartwright, \& Sprately, 1996).

\section{Treatment Alliance and Treatment Engagement}

Studies in this area have focused on the helping relationship established in the first assessment interview and subsequent treatment entry, as well as on the links between the treatment alliance and how long patients remain in treatment and whether or not they complete treatment.

1. When a stronger helping relationship is established at the initial intake or assessment interview, the patient is more likely to enter treatment.

Empirical evidence that clients with substance use disorders may respond positively to a counselor's respect and understanding was first obtained more than 40 years ago. In an initial study, Chafetz and his colleagues (1962) showed that treating alcoholic patients with respect and interest led to improved treatment attendance. In a follow-up study, emergency room physicians who were responsible for referring alcoholic individuals to treatment were asked to describe their experiences with these patients. Physicians who were judged to be more anxious and less angry were more successful in referring alcoholic patients for specialty treatment; that is, the patients they saw were more likely to make and keep at least one appointment for alcoholism treatment. Anxiety on the part of the physician was thought to communicate greater concern for the patient, whereas anger likely resulted in the patient experiencing rejection (Milmoe, Rosenthal, Blane et al., 1967).

When a client applies for treatment, the quality of the intake assessment interview may be especially important. In a study of alcohol treatment, Hyams et al. (1996) asked clients to use the Client Experiences and Satisfaction Questionnaire to describe the quality of the relationship a counselor established with them during an initial intake interview. Clients who felt more at ease with their counselor, and who felt that their counselor liked and understood them and was warm and friendly toward them, were more likely to subsequently engage in treatment. In contrast, clients who felt that their counselor lacked genuineness, criticized and looked down on them, or withheld information from them, were less likely to engage in treatment.

2. When a stronger alliance is established, the client is likely to remain in treatment longer and to complete the treatment episode.

In their studies of clients with drug use disorders, Simpson and colleagues noted that a stronger treatment alliance was associated with enhanced attendance in the first two months of treatment, which was associated with a stronger subsequent treatment alliance (Joe, Simpson, Greener, \& Rowan-Szal, 1999). Counselors' ratings of a good alliance in the first two months of treatment, and clients' treatment attendance in the first two months, predicted the length of treatment (Simpson, Joe, Rowan-Szal, \& Greener, 1997). Moreover, counselors' ratings of clients' motivation early in treatment predicted which clients remained in treatment for one year or more (Simpson, Joe, \& Rowan-Szal, 1997). 
In another sample of clients with substance use disorders, higher HAQ Cooperation subscale scores were associated with a greater likelihood of completing detoxification. In addition, clients who were contemplating leaving treatment scored lower on cooperation than clients who were not contemplating leaving (De Weert-Van Oene, Jorg, \& Schrijvers, 1999). Among couples in conjoint alcoholism treatment, a stronger treatment alliance, as measured by the VTAS and VNIS, was associated with greater session attendance and treatment completion (Raytek, Epstein, \& Hirsch, 1999).

The association between alliance and treatment retention may be stronger for clients entering a new treatment episode. In Project MATCH, WAI total scores from both the therapist and the client were positively related to the duration of treatment among outpatients, even after controlling for client and therapist characteristics, client drinking history, treatment site, and treatment modality. However, neither the client's nor the therapist's WAI total scores were associated with treatment participation among aftercare clients (Connors, DiClemente, Longabaugh, \& Donovan, 1997). The treatment alliance may be less salient for patients who have just completed a prior treatment episode, as was true for the aftercare patients, than for patients who are entering a new treatment episode, as was the case for the outpatients.

The strength of the association between alliance and retention may also depend on client characteristics. In a study of opioid-dependent clients, therapists' ratings of the treatment alliance on the HAQ-II after three or more sessions was associated with treatment completion for clients. with moderate to severe psychiatric problems; this relationship did not hold for those with few psychiatric symptoms. More than $75 \%$ of clients who developed a strong alliance completed treatment, whereas this was true of less than $25 \%$ of clients who developed a weak alliance (Petry \& Bickel, 1999). These findings are consistent with the idea that clients who have more severe problems, are in more distress, and/or have fewer social resources, may be more dependent on the therapist and thus remain in treatment longer.
Treatment Alliance and Proximal Duringtreatment Outcomes

Studies in this area have considered the associations between treatment alliance, patients' mood and distress, patients' use of substances while in treatment, and the extent to which patients actively explore their problems during treatment.

3. When a stronger alliance is established, the client is more likely to explore problems in treatment. When the therapist is more confrontational, the client is more likely to show negative in-treatment behavior.

There is a relationship between the therapist's verbal behavior and the patient's immediate responses in the treatment session. Counselors who listen and offer restructuring comments are likely to elicit positive and on-task comments; in contrast, those who are more confrontational (that is, who disagree with clients and openly challenge their motivations and substance use) are more likely to elicit argumentative and negative behavior, interruptions, and off-task comments (Miller, Benefield, \& Tonigan, 1993). Client-therapist cooperation, as measured by the HAQ, is positively associated with clients' work in treatment to resolve their problems (De Weert-Van Oene et al., 1999).

As part of the Drug Abuse Treatment Outcome Study (DATOS), more than 2,500 clients were studied in long-term residential treatment, outpatient drug-free treatment, or outpatient methadone treatment. In each of these three treatment modalities, clients' ratings of rapport with their counselors were positively associated with clients' reports of their confidence in and commitment to treatment (Broome, Simpson, \& Joe, 1999).

4. When a stronger alliance is established, the client tends to experience less distress and more pleasant mood during treatment.

In a sample of cocaine-dependent outpatients, clients' ratings of treatment alliance at the second and fifth treatment sessions predicted lower distress one month after treatment entry and lower depression after one month and six months. Ther- 
apists' ratings of a stronger alliance at the second and fifth sessions were associated with less client distress and depression at six months. However, the connection between fifth-session treatment alliance and one-month outcome was not due to early symptomatic improvement (Barber et al., 1999).

Ojehagen, Berglund, and Hansson (1997) found a positive relationship between client-therapist alliance, as rated by independent observers from tape recordings of the third session of multimodal behavior therapy, and clients' pleasant mood, extroversion, and control after six months of treatment. This relationship did not exist for clients in psychodynamic treatment, perhaps because this treatment modality places less emphasis on clients' immediate affect. In a study of alcoholic clients, De Weert-Van Oene et al. (1999) identified a strong positive association between the helping relationship and clients' improved mood.

5. When the therapist establishes a stronger alliance with the patient, the'patient is more likely to abstain from alcohol and drugs during treatment and show more improvement in patterns of use of other substances.

In Project MATCH, among outpatients with alcohol use disorders, WAI total scores, whether provided by the client or the therapist, predicted a higher percentage of days abstinent and fewer drinks per drinking day during treatment. In contrast, among aftercare clients, only therapists' WAI scores were associated with a higher percentage of abstinent days (Connors et al., 1997). The weaker association in the aftercare sample may reflect the fact that these clients had $90 \%$ abstinence days one month after treatment (Project MATCH Research Group, 1997).

Among clients in drug treatment, counselors' ratings of the therapeutic alliance were associated with less drug use during treatment, which, in turn, was related to better long-term treatment retention (Simpson, Joe, Rowan-Szal, \& Greener, 1997). Counselors' ratings of the alliance were also associated with less cocaine use at 3-month and 6month follow-ups, at which time many of the clients remained in treatment (Joe, Simpson, Greener, \& Rowan-Szal, 1999).
Among clients in methadone maintenance, HAQ-II alliance scores after three months of treatment, as rated by the client or the therapist, were associated with lower Addiction Severity Index (ASI) drug use composite scores and a higher likelihood of drug-free urine specimens at three and six months of treatment. Clients who reported less drug use and had more drug-free urine specimens during the 30 days prior to the 3-month HAQ assessment rated the helping alliance more positively. This suggests a positive feedback loop in which a client's early treatment progress enhances the alliance, which, in turn, enhances subsequent in-treatment outcome (Belding et al., 1997). In a study of methadone detoxification, clients' CALPAS ratings of the treatment alliance were associated with reduced use of illicit opioids and less needle sharing (Tunis, Delucchi, Schwartz, Banys, \& Sees, 1995).

Four observer-rated alliance measures (the Penn Helping Alliance Rating Scale, the CALPAS, the VTAS, and the WAI) were used in a randomized trial comparing cognitive-behavioral treatment and 12-step facilitation treatment for individuals with co-morbid cocaine and alcohol use disorders. Clients and therapists also used the WAI to rate the helping alliance after the third treatment session. The four observer ratings of alliance were moderately to strongly correlated, and all four were correlated with consecutive days abstinent from cocaine while in treatment. However, neither the clients' nor the therapists' perceptions of the alliance were associated with this outcome (Fenton, Nich, Frankforter, \& Carroll, 2001).

In a study of cocaine-dependent patients in a controlled treatment trial, patients in a usual care or clinical management condition who developed a stronger treatment alliance by the second session of treatment, as rated by observers on the VTAS, reported more days of abstinence from drugs and had more drug-free urine screens (Carroll, Nich, \& Rounsaville, 1997). In general, these findings held for all three of the VTAS subscales and for the VTAS total score. Among patients in the cognitive-behavioral arm of the trial, however, there were no associations between treatment alliance and these outcomes (Carroll et al., 1997). A positive alliance may have a stronger influence on outcomes in treatments in which the active ingredients are common factors as compared with 
treatments that include more specific active ingredients, such as cognitive-behavioral therapy.

\section{Treatment Alliance and Longer \\ Term Outcome}

Research investigating the association between treatment alliance and posttreatment functioning have focused on several outcome variables, including symptom reduction, level of substance use, and employment functioning.

6. When the therapist establishes a stronger alliance with the client, the client tends to experience better outcomes related to substance use.

Both counselor and client ratings of the therapeutic relationship have been associated with treatment outcomes among clients with drug use disorders. In two cohorts, counselors rated their rapport with the client, as reflected in their ratings of the client as easier to talk to, warm, caring, honest, and sincere. These ratings, which were averaged over several occasions during the first year of treatment, were associated with a lower likelihood of using drugs, of being illegally involved with drugs, and of having been arrested at 12- and 18month follow-ups (Joe, Simpson, Dansereau, \& Rowan-Szal, 2001). In addition, clients' retrospective ratings of their respect for the counselor were associated with better attendance in the first two months of treatment, which predicted a longer duration of treatment, and, in turn, was associated with better 12-month drug use and criminal activity outcomes (Simpson, Joe, Greener, \& RowanSzal, 2000).

Among drug-dependent patients in methadone treatment, Luborsky and his colleagues (1985) identified strong associations between patients' HAQ ratings of the helping alliance after the third treatment session and patients' 7-month treatment outcomes. Specifically, patients who established a stronger alliance experienced better drug use, legal, psychological, and employment outcomes.

Based on counselors' written responses about how they would handle specific client situations, Valle (1981) asked observers to rate counselors' interpersonal functioning with respect to empathy, genuineness, respect, and specificity and directness in expressing feelings. Clients whose counselors were higher in interpersonal functioning were less likely to relapse, had fewer relapses, and were less likely to use alcohol during the two years after treatment. Conversely, Miller et al. (1993) found that clients of therapists who were more confrontational tended to consume more alcohol at a 12month follow-up.

In the Project MATCH outpatient sample, WAI scores, whether provided by the patient or the therapist, were associated with a higher percentage of days abstinent and fewer drinks per drinking day at the 12-month follow-up. In the aftercare sample, only therapists' WAI scores were associated with a higher percentage of days abstinent at the 12-month follow-up (Connors et al., 1997). As noted earlier, the weaker findings among the aftercare patients may reflect the fact that they had just completed an intensive course of alcoholism treatment.

In an examination of the effectiveness of cognitive-behavioral treatment for substance use disorders in a community setting, treatment alliance was measured by asking the patient to complete the HAQ at the end of treatment and having an observer complete the Bond Subscale of the WAI on the basis of the patient-therapist relationship in the second session. Stronger treatment alliance, as judged by either of these measures, was associated with a higher likelihood of abstinence and fewer negative consequences of substance use at a nine-month follow-up (Morgenstern, Blanchard, Morgan, Labouvie, \& Hayaki, 2001).

Therapeutic alliance also seems to predict posttreatment outcome for bulimia nervosa. Wilson et al. (1999) found that a greater overall treatment alliance predicted symptom remission of women with bulimia, although their subsequent temporal analysis of the pattern of change suggested "it was prior symptom change that more consistently influenced client ratings of the therapeutic alliance than vice versa" (p. 458).

In another bulimia treatment study, which compared motivation enhancement therapy with cognitive behavioral therapy, clients' ratings of agreement with the therapist on the goals and tasks of the therapeutic alliance, as measured by the WAI, predicted reduced binge eating and vomiting (Treasure et al., 1999). The authors hypothesized that clients' readiness to change influences both 
the clients' ability to develop a therapeutic alliance and treatment outcome.

A few studies have failed to show a relationship between treatment alliance and posttreatment outcomes for drug and alcohol use (Barber, Luborsky, et al., 2001; Long, Midgley, \& Hollin, 2000; Ojehagen et al., 1997; Raytek et al., 1999) or in the treatment of bulimia nervosa (Wilson, Fairburn, Agras, Walsh, \& Kraemer, 2002). We were not able to find reasons for these discrepant findings in the study or analytic design, therapeutic alliance measure used, method of measurement (i.e., self-report vs. observer rating), or cohort demographics. Future research is needed to specify the conditions under which alliance is or is not related to longer term substance use and eating disorder outcomes.

7. A strong treatment alliance may have an especially beneficial influence on specific subgroups of patients, such as those who have an antisocial personality or have high levels of anger.

Patients with substance use disorders who also have an Antisocial Personality Disorder may find it especially difficult to establish interpersonal relationships. Accordingly, when such patients do establish a working alliance in treatment, they may experience better outcome. This idea was supported in a study of patients who had both substance use and personality disorders and were seen for 24 weeks of treatment and evaluated at a 7month follow-up. The patient's perception of the treatment alliance, as measured by the HAQ after the third treatment session, was associated with better 7-month drug and employment outcomes, and the therapist's perception was associated with better employment outcomes (Gerstley et al., 1989).

In the sample of outpatients drawn from Project MATCH, those who were high in anger fared better on both 1-year and 3-year outcomes after being treated with Motivational Enhancement Therapy (MET) than after either cognitivebehavioral or 12-step facilitation treatment. Among clients who were high in anger, those treated in MET had an average of $76 \%$ abstinent days, whereas their counterparts in the other two treatments averaged $66 \%$ abstinent days. Con- versely, clients low in anger performed better after cognitive-behavioral or 12-step facilitation treatment than after treatment in MET (Project MATCH Research Group, 1998). These findings imply that therapist empathy and the specific therapist behaviors prevalent in MET, such as not confronting resistance directly and avoiding argumentation, may have led to enhanced treatment alliance, engagement, and positive change.

\section{Other Relational Variables}

in Psychotherapy

Therapist-client relational variables other than the therapeutic alliance influence psychotherapy process and outcome. The American Psychological Association's Division of Psychotherapy's Task Force on Empirically Supported Therapy Relationships (Norcross, 2002a) identified a set of relationship variables that has been shown to have an impact, and a second set that is promising. We review these variables and some relevant findings here. These variables seem likely to be important in the treatment of patients with substance use disorders, but only a few of these variables have been sufficiently studied in this context to derive specific principles of change based on them.

The Task Force lists empathy, goal consensus and collaboration, and cohesion in group therapy as important aspects of the therapy relationship that have a clear impact on treatment. According to a recent meta-analysis, Empathy, or clients' and observers' perceptions that therapists understand their clients'. internal experiences, accounts for $10 \%$ of the variance in treatment outcome (Bohart, Elliott, Greenberg \& Watson, 2002). Goal consensus and collaboration, including agreement on therapeutic goals, patient cooperation, active patient involvement, homework compliance, and cooperation and affiliation between therapist and patient, also clearly enhances psychotherapy outcome (Tryon \& Winograd, 2002). Cohesion in group psychotherapy, which is facilitated by pregroup preparation, early group structure, leader interaction, feedback, leader modeling, and participant emotional expression, is similarly associated with positive patient outcome in group therapy (Burlingame, Fuhriman \& Johnson, 2002).

The Task Force points to several other relationship factors that may be associated with outcome. 
Positive regard, which appears to facilitate a longterm working relationship, is associated with enhanced treatment outcome when patients' perspectives on outcome are highlighted (Farber \& Lane, 2002). Congruence or genuineness predicted positive psychotherapy outcome in 34\% (26 out of 77 ) of studies, while $66 \%$ (51 out of 77) produced null results (Klein, Kolden, Michels, \& Chisholm-Stockard, 2002). While feedback has not been heavily studied, existing research has found a generally positive effect on outcome (Claiborn, Goodyear \& Horner, 2002).

Research on the repair of alliance ruptures, although in an early stage of development, suggests that specific processes such as patient expression of negative feelings or therapists' nondefensive behavior are associated with improved alliance and treatment outcome (Safran, Muran, Samstag \& Stevens, 2002). Therapist self-disclosure appears helpful to patients in the immediate process of psychotherapy (Hill \& Knox, 2002). Management of countertransference, which includes such factors as self-insight, self-integration, anxiety management, empathy, and conceptualizing ability, facilitates treatment, whereas countertransference acting out hinders treatment (Gelso \& Hayes, 2002). Finally, greater quality of relational interpretations is associated with more positive treatment outcome, especially when therapists accurately address central aspects of patients' interpersonal dynamics (Crits-Christoph \& Gibbons, 2002).

In the context of substance use disorders, there is very little research on relational elements of the therapy process other than the therapeutic alliance. The major exception lies in the research concerned with the relationship variables identified by Rogers: therapist empathy, positive regard, and congruence. Several of the studies we have already considered in the context of discussing the research concerned with the therapeutic alliance also confirm the importance of these variables for process and outcome in the context of substance use disorders (e.g. Chafetz et al., 1962; Hyams et al., 1996; Miller et al., 1993; Milmoe et al., 1967; Valle, 1981). These studies suggest the following principle:

8. Therapist empathy, positive regard, and congruence have a positive impact on ther- apy process and on client outcomes in therapy for substance use disorders.

Despite the paucity of research to date on many of the variables identified by the Division 29 Task Force in the context of substance use disorders, we predict that the conclusions reached by the Division 29 Task Force on the importance of these variables in other psychotherapy research contexts are likely to hold for substance use disorder treatment. Yet, we also believe that it is especially important to document the impact of these variables in the context of substance use disorders. Because many clients with substance use disorders seek treatment due to external factors such as pressures from family, employers, or the judicial system, these aspects of the therapist-client relationship may have a different degree of influence on them than on other groups of more highly motivated patients.

\section{The Broader Context of Treatment}

Many clients with substance use disorders are seen in residential and group treatment; in fact, the therapeutic community is a primary modality of treatment for drug abuse (De Leon; 1997; Jones, 1953). The concept of "community as doctor" (Rapoport, 1960) asserts that relationships with treatment peers and staff members are key aspects of the healing process. A substantial body of literature demonstrates that better interpersonal relationships in residential treatment programs are associated with more favorable in-program and post-program outcome for clients with a variety of diagnoses (Moos, 1997).

\section{When treatment programs create a} stronger alliance with patients (that is, are involving, supportive, and expressive), patients are more likely to remain in treatment and to have better in-program outcomes.

Indices of client involvement, support, and expressiveness in residential treatment programs tap a construct that is comparable to the therapistclient alliance. With respect to in-treatment outcomes, when programs are more involving and supportive, clients tend to be more satisfied with 
treatment, show more self-confidence and less aggressive behavior, are more affiliative and selfrevealing, and engage in more activity and social interaction. They are also less likely to drop out of treatment (Moos, 1997).

Among clients with alcohol use disorders, those who rated a Salvation Army treatment program as more involving and supportive were less likely to drop out (Moos, Mehren, \& Moos, 1978). According to Linn (1978), older alcoholic clients who perceived more program involvement and support were less likely to leave the program prematurely. In addition, Linn and her colleagues (1979) found that African-American clients with drugdependence disorders who saw their program as more expressive were more likely to remain in treatment. However, these findings did not hold for younger clients or for Caucasian clients, suggesting that relationship quality may be especially important for clients who are members of minority groups, such as older clients and African-American clients.

The quality of the treatment alliance also seems to influence treatment engagement for women treated for eating disorders in residential programs. For example, Gallop, Kennedy, and Stern (1994) found that clients who remained in a residential treatment program perceived their therapeutic alliance with staff to be significantly stronger than clients who left the program; in addition, clients who remained in treatment reported their therapeutic alliance became stronger over time.

10. When treatment programs create a stronger alliance with patients (that is, are involving, supportive, and expressive), patients are likely to have more positive discharge and post-program outcomes.

Alcohol use disorder clients' perceptions of support in hospital-based programs are associated with better discharge outcomes-fewer psychological symptoms, less positive expectations for substance use, more positive expectations for quitting, and more reliance on approach coping (Lemke \& Moos, 2002; Ouimette, Ahrens, Moos, \& Finney, 1998). Perceived closeness to peers in treatment is associated with longer treatment length and reduced relapse rates (Machell, 1987). In community-based programs, clients who estab- lish more supportive relationships with other clients are more likely to complete the program, to have a stable residence and be employed at discharge, and to instill staff members' confidence that they will recover (Moos \& King, 1997).

When post-program outcomes are considered, clients with alcohol use disorders who rated their program more positively overall (including higher involvement, support, and expressiveness) consumed less alcohol and had fewer drinking problems at a six-month follow-up (Moos, Finney, \& Cronkite, 1990). Impressively, clients who appraised their program more positively consumed less alcohol and had fewer physical symptoms and less depression 10 years later (Finney \& Moos, 1992). In another study, alcoholic clients' perceived treatment involvement was associated with better outcome one year after treatment (Long, Williams, Midgley, \& Hollin, 2000). Although the precise mechanisms remain to be determined, clients' perceptions of their treatment programs may provide important information about their integration into the program; additionally, they may provide evidence about their characteristic ways of adapting to new social contexts that predict longterm functioning.

\section{THE ROLE OF THE CLIENT'S RELATIONSHIPS WITH FAMILY AND PEERS}

In the treatment of substance use disorders, the relationship between client and therapist is only one of the relationships that assume importance as factors affecting treatment process and outcome. The relationships that clients have with their families, their relationships with peers in treatment, and the relationships of family and friends to treatment also exert considerable influence on client outcomes.

11. Clients who indicate they receive general social support and support for reduced substance use during the time of treatment experience better treatment outçomes.

As Westerberg (1998) notes, social support can function in two different ways-either as a positive outcome factor (when the client's social net- 
work offers support for reduced substance use) or as a negative outcome factor (when the client's social network itself abuses substances or is not supportive of reduced substance use). Considerable evidence exists for the importance of social support in enhancing client outcomes for each of the substance use disorders, and research has also linked poor social support with poorer long-term outcomes (Breteler, Van Den Hurk, Schippers, \& Meerkerk, 1996).

Examining the outcomes of treatments for different substance use disorders, McLellan et al. (1997) found high social support to be an important predictor of better outcome among 649 clients in opiate, cocaine, and alcohol treatments. Clients reporting more severe family problems at admission also had poorer social adjustment at follow-up.

In the context of Project MATCH, clients in alcohol treatment who received more social support, or had more abstainers or recovering alcoholics in their social networks, had better outcomes (Zywiak, Longabaugh, \& Wirtz, 2002).

In another study of alcohol treatment, Booth, Russell, Soucek, and Laughlin (1992) showed that higher levels of reassurance from family and friends were associated with increased time to readmission. In the context of treatment of drug use disorders, couple factors, such as the partner's poor coping strategy for dealing with their partner's drug problem (Barber, 1995) and negative communication within the marriage (Fals-Stewart \& Birchler, 1998) have also been associated with more frequent posttreatment drug use.

In the context of smoking cessation, Collins, Emont, and Zywiak (1990) found clients who reported more support and fewer hindrances from friends just after stopping smoking were less likely to return to smoking three months and six months after quitting. Similarly, Morgan, Ashenberg, and Fisher (1988) found at 2, 3, and 8 weeks following cessation from smoking, participants reported the frequencies of specific behaviors from their spouses, families, and friends were significantly related to outcome at 13-weeks post-cessation. Compared with recidivists, abstainers reported their friends exhibited more helping behaviors, and less prompting of or modeling of smoking, throughout the maintenance period. In an investigation of short- and long-term relapse rates, so- cial support for quitting smoking was the only variable that predicted both initial and sustained quitting up to 24 months after treatment ended (Nides et al., 1995).

Hanson, Issacsson, Janzon, and Liddle (1990) found that emotional support was particularly associated with successful long-term abstinence from smoking in elderly men, while the presence of a smoking spouse increased the rate of relapse. Lichtenstein, Glasgow, and Abrams (1986), in a series of studies with three different samples, also linked greater social support to better outcomes.

\section{Clients who are part of non-substance-} abusing networks have better outcomes.

In Project MATCH, clients whose social networks included more abstainers or recovering alcoholics showed better outcomes (Zywiak et al., 2002). Furthermore, clients' support networks differentially influenced the efficacy of the various treatment forms: clients who reported more drinking among people in their social networks did better in 12-step Facilitation than in Motivational Enhancement Therapy.

Curry, Thompson, Sexton, and Omenn (1989) found similar patterns in smoking cessation: those who achieve long-term abstinence from smoking report a fewer number of smokers in their environments.

13. Spouse and family involvement in treatment may help engage the client in treatment; the effects are particularly pronounced when that client is not initially ready to participate in treatment.

In their review of family-based treatment methods for alcoholism, Edwards and Steinglass (1995) conclude that involving spouses and family in treatment increases the rate of client engagement in therapy, particularly for those individuals with alcohol use problems who are not ready to engage in therapy. A more recent review by O'Farrell and Fals-Stewart (2002) reaches similar conclusions.

Several studies have examined methods for helping the alcoholic's family engage the alcoholic in treatment. In a pilot study of their Community Intervention Training method, which includes coaching spouses in methods for reinforcing sobri- 
ety and in how to help the alcoholic engage in treatment, Sisson and Azrin (1986) found 86\% of alcoholics engaged in treatment as compared to none in a more traditional program. In a randomized clinical trial, Miller, Meyers, and Tonigan (1999) compared three manual-guided treatment approaches aimed at helping concerned significant others engage unmotivated problem drinkers in treatment. Follow-up analyses indicated that the community reinforcement and family training approach (CRAFT) was more successful at engaging problem drinkers in treatment (64\%) compared to traditional Al-Anon (13\%) (which does not have a goal of engaging the problem drinker in treatment) and an alternative strategy developed at the Johnson Institute for training family in how to hold a highly confrontational meeting with the person with the substance use problem aimed at having that person engage in treatment (30\%).

In another pilot study evaluating a low confrontation method called "Unilateral Family Therapy"-which only utilizes meetings with the family of the alcoholic-Thomas, Santa; Bronson, and Osterman (1987) found $61 \%$ of the alcoholics whose spouses participated in treatment either subsequently engaged in treatment or reduced their drinking. In a larger follow-up study, Thomas, Yoshioka, Ager, and Adams (1990) found that individuals whose spouses participated in Unilateral Family Therapy entered therapy more often than those whose spouses did not participate.

Examining the more dramatic "Intervention" method of the Johnson Institute described above in a pilot study, Liepman, Nirenberg, and Begin (1989) trained 24 families in strategies for confronting the alcoholic. Six of the seven families who went on to conduct the "intervention" succeeded in engaging the alcoholic in treatment. However, only 7 of the original 24 families actually went on to hold an intervention meeting with the problem drinker. A similar pattern of findings emerges for this method in the Miller et al. study (1999) reviewed above; although the "intervention" sessions were effective in engaging the substance abuser in treatment when held; few of those receiving the preparation for these meetings went on to actually hold an intervention session. Thus, on the whole the Johnson Institute method appears to only result in the engagement of a small percentage of problem drinkers in treatment.
In another clinical trial, Dakof et al. (in press) found a family-based manualized in-home drug treatment, called "Engaging Moms," resulted in greater enrollment in drug treatment than a control condition ( $86 \%$ vs. $46 \%$ ) for women with substance use disorders.

Outside the realm of this review, but striking in their impact, are exceptional rates of engagement in therapy for adolescents with substance use disorders through methods of assertive family engagement: Szapocznik et al. (1988), Santisteban et al. (1996), Donohue et al. (1998), Waldron, Slesnick, Brody, Turner, and Peterson (2001) and Henggeler, Pickrel, Brondino, and Crouch (1996) have all reported high rates of treatment engagement and completion utilizing these methods compared to the typical rates in individual treatment for adolescents with these disorders.

14. Spouse and family involvement in treatment may help produce better outcomes.

O'Farrell and Fals-Stewart (2002) and O'Farrell and Feehan (1999), in summarizing the literature on spousal involvement in the treatment of alcohol use disorders, conclude that involvement of spouses in treatment has been associated with improved family functioning in a variety of domains, including reduced family stressors; improved marital adjustment; reduced domestic violence and verbal conflict; reduced risk of separation and divorce; improvement in important family processes related to cohesion, conflict, and caring; reduced emotional distress in spouses; and reductions in drinking and recidivism.

Several methods that have included spouse involvement have produced superior outcomes in the treatment of alcohol use disorders compared to more traditional individual treatments. The Counseling for Alcoholics Marriage Project (CALM) has developed relationship focused interventions with couples that have proved efficacious in several randomized trials (O'Farrell and Fals-Stewart, 2002). For example, in a comparison of Behavioral Marital Therapy (BMT) with individual alcoholism counseling, O'Farrell et al. (1993) found BMT produced better marital and alcohol use outcomes during and immediately after treatment than individual counseling alone. Fals-Stewart, Birchler, and O'Farrell (1996) found 
that married or cohabiting men with substance use disorders who participated in behavioral couples therapy in addition to individual-based treatment had fewer days of substance use and, along with their partners, reported higher levels of dyadic adjustment during and one year after treatment than men who received the individual intervention. Compared to the individually treated clients, men in the couple therapy showed significant reductions in substance use, and couples showed greater improvement in dyadic adjustment (Fals-Stewart et al., 2000).

Kelley and Fals-Stewart (2002) found Behavioral Couples Therapy (BCT) produced greater reductions in substance use and more gains in relationship adjustment than did individually based treatment or a psychoeducation control group. In yet another study, O'Farrell and Birchler (2001) found both BCT and a brief BCT were more effective in reducing substance use and increasing relationship satisfaction than individual therapy or a psychoeducational placebo control.

McCrady et al. (1986) compared treatment effects for individuals with alcohol use disorders and their spouses among three outpatient behavioral treatment conditions: minimal spouse involvement, alcohol-focused spouse involvement, or alcohol-focused spouse involvement plus behavioral marital therapy. At follow-up, all clients markedly decreased their drinking and reported increased life satisfaction. Clients receiving marital therapy were more compliant than those receiving only the alcohol-focused spouse involvement, were more likely to stay in treatment, decreased their drinking more quickly in treatment, relapsed more slowly after treatment, and maintained better marital satisfaction.

Although there now are many studies documenting the efficacy of family approaches to adolescent substance abuse (Liddle \& Dakof, 1995; Rowe \& Liddle, 2002), limited research exists on family involvement in the treatment of adults with drug use disorders other than those focused on alcohol. In an early study of opiate-dependent clients, Stanton and Todd (1979) found structuralstrategic family therapy more effective than standard drug counseling. Galanter (1993) found a network approach for treating substance abuse that involved family and peer support was effective for 45 of 60 clients.
Some research has shown less pronounced effects for couple and family intervention, particularly with long-term follow-up. McCrady, Longabaugh, Noel; and Beattie (1987) compared treatments offered to alcohol-misusing clients seen alone, clients seen with family, and clients seen with co-workers. Family involvement proved no more effective than the individual treatment, although a trend existed for those receiving the family intervention to respond more quickly to treatment. McCrady, Paolino, Longabaugh, and Rossi (1979) found higher initial rates of abstinence in couple treatment than individual treatment for alcohol use disorder than for individual treatment, but the differences were not statistically significant and were not found at the four-year followup (McCrady, Moreau, Paolino, \& Longabaugh, 1982).

Winters, Fals-Stewart, O'Farrell, Birchler, and Kelley (2002) randomly assigned married or cohabiting female drug-abusing clients to either a behavioral couples therapy condition or to an equally intensive individual-based treatment condition. During most of the one-year follow-up, those who received the couples therapy reported fewer days of substance use; longer periods of continuous abstinence; lower levels of alcohol, drug, and family problems; and higher relationship satisfaction compared with participants who received the individual therapy. However, in this study, as in McCrady et al. (1979), differences in relationship satisfaction and number of days of substance use dissipated over the course of the posttreatment follow-up period and were not significantly different by the end of one year.

15. The impact of family involvement in treatment may be complex, greatly affected by the interaction of client, therapy, and family variables.

Longabaugh, Wirtz, Beattie, Noel, and Stout (1995), examining treatment matching variables, recommend that the appropriate dose of relationship-enhancement treatment for alcohol use disorders should be determined based on an initial assessment of the client's relationships. They compared three treatments with different relationship-enhancement intensities: individual extended cognitive-behavioral $(\mathrm{ECB}$, with no 
relationship-enhancement component); brief broad-spectrum (BBS, which included four sessions of partner therapy with one or more significant others); and extended relationship enhancement (ERE, which included eight sessions of partner therapy). They found that ERE was more effective in increasing abstinence for clients entering treatment with low levels of affiliative social investment or a network unsupportive of abstinence, while BBS was more effective for clients with either (a) low involvement in a social network unsupportive of abstinence or (b) high investment in a network supportive of abstinence. ECB outcomes were "neither as good as those correctly matched nor as bad as those mismatched to the different exposures of relationship enhancement" (p. 296).

The differential impact of involving family in treatment may also depend on the outcome studied. O'Farrell, Cutter, and Floyd (1985) compared two marital therapies with an individual therapy for alcohol-related problems. All three treatments reduced drinking behavior equally well. However, only the marital therapies affected marital functioning. It appears that the effects of couple intervention may uniquely target the marriage, and these effects may, in turn, lay the foundation for future "sleeper" effects on the targeted drinking behavior.

A fascinating study by Longabaugh, Beattie, Noel, Stout, and Malloy (1993) suggests that intervention pathways may be also affected by individual differences in marriage. Longabaugh et al. (1993) compared a behavioral treatment for alcohol use problems with a relationship-enhanced version including sessions with spouses. Individuals who were highly invested in their relationships and perceived a high level of support from their significant other showed great improvement; as did individuals who reported low investment in their relationships. However, those with high relationship investment and low levels of support did less well. The impact of couple intervention may be mediated by the value of the relationship to the individual.

16. Involving a supportive sponsor/peer in treatment results in better outcomes.

Interventions designed for alcohol and drug misuse, smoking cessation, and binge eating have all demonstrated the value of involving a supportive peer or sponsor in treatment. Most prominently, in a meta-analytic review of studies of Alcoholics Anonymous (AA), having an AA sponsor was strongly related to drinking outcomes (Emrick, Tonigan, Montgomery, \& Little, 1993).

Gordon and Zrull (1991) studied the social networks of 156 inpatients treated for alcohol use disorders, and found that co-workers were more active as participants in treatment than were clients' family and friends. Factors influential in recovery included active support from co-workers who did not drink regularly with the client as well as the level of perceived social support from family and friends.

Gruder et al. (1993) recruited smokers who registered for a televised smoking cessation intervention program into three treatment conditions: social support, in which participants were trained in support and relapse prevention with a nonsmoking buddy; a discussion condition, in which participants and their non-smoking buddies attended separate support groups; and a no-contact control condition, in which participants viewed the television program and were given a self-help manual, but did not have contact with a nonsmoking buddy. Abstinence rates were highest in the social support group compared to the discussion group, no-shows, and no-contact controls. The social support improved outcome by increasing both the level of support for quitting and program material use.

Interestingly, men and women treated for smoking cessation may respond differently to the involvement of a supportive peer. Nides et al. (1995) found that men who brought a support person along to their treatment orientation session were more likely to quit initially and resist relapse after 12 months, while bringing a support person was not related to women's initial quitting and relapse rates.

Most research has focused on the treatment involvement of a peer or sponsor chosen by the client, but Porzelius et al. (1995) created peer support within a treatment they designed for binge eating, obese binge eating treatment (OBET). In order to foster peer support within the treatment, they divided clients into small groups of two or three during weekly sessions and asked them to share experiences and problem solve together. 
When they compared OBET to a standard behavioral weight loss treatment, they found women with severe binge eating lost more weight by the 12-month follow-up in OBET. Although women with moderate binge eating lost more weight initially in the standard treatment, and women who did not binge eat initially responded equally well to both treatments, neither of these groups were able to maintain their weight loss at the 12 -month follow-up.

However, not all studies have found involving a peer or sponsor in treatment to have a positive effect on outcome. Crape, Latkin, Laris, and Knowlton (2002), in their study of 500 former and current injection drug users treated in Narcotics Anonymous or Alcoholics Anonymous, found that having a sponsor was not associated with any improvement in one year sustained abstinence rates compared to non-sponsored controls. However, being a sponsor-or being involved in religious or community organizations-was strongly associated with substantial improvements in sustained abstinence rates, even after controlling for such variables as NA/AA meeting attendance, marital status, participation in drug and alcohol treatment centers, and HIV status.

Other studies have suggested there may be interaction effects between the involvement of a 12-step self-help group sponsor and treatment type. In a study of smoking cessation treatment - for participants with a history of alcohol use disorders, Patten, Martin, Calfas, Lento, and Wolter (2001) found that standard treatment was more effective for participants with an active 12-step sponsor, whereas behavioral counseling plus exercise and behavioral counseling plus nicotine gum were more effective for those without an active sponsor.

17. Peer and family involvement in programs of formal and informal care and relapse prevention may increase the likelihood of stable remission. Stabilizing and enhancing clients' community support systems can help to maintain psychosocial functioning and enhance the likelihood of stable remission.

A major problem in the treatment of substance use disorders involves the high rate of recidivism. This has led to specific efforts to prevent relapse, some of which have involved family participation. The literature examining the impact of family involvement in relapse prevention is small but encouraging.

Ossip-Klein, Van Landingham, Prue, and Rychtarik (1984) assessed the impact of a familybased incentive program for aftercare attendance after completion of an inpatient alcohol program. The family involvement program fostered better attendance in aftercare and better alcohol-related outcomes.

O'Farrell, Choquette, and Cutter (1998) found BMT for clients with alcohol use disorders was more effective when it included follow-up relapse prevention sessions than when it did not. BMT plus relapse prevention involving the family led to more days abstinent and greater use of an Antabuse contract than BMT alone, and these outcomes lasted through an 18-month follow-up. BMT plus relapse prevention also produced better wives' marital adjustment than BMT alone throughout the 30 months of follow-up. Irrespective of treatment condition, more use of BMTtargeted marital behaviors was associated with better marital and drinking outcomes throughout the 30-month follow-up period. Alcoholics with more severe marital problems had more abstinent days and maintained relatively stable levels of abstinence if they received BMT plus relapse prevention.

Not all studies have shown similar effects. Perri et al. (1987) attempted to evaluate the effectiveness of two posttreatment programs designed to help clients maintain their weight loss. They randomly assigned clients who had participated in a 20-week group weight loss treatment to behavior therapy without follow-up, behavior therapy plus a therapist-contact posttreatment program, or behavior therapy plus a peer-support posttreatment program. Although the therapist-contact condition showed significantly greater weight loss maintenance at a 7 -month follow-up, by 18 months relapse rates were equivalent across conditions. In a study of alcohol treatment, McCrady, Epstein, and Hirsch (1999) found Alcohol Behavioral Marital Therapy with relapse prevention no more effective than without. 


\section{DISCUSSION}

The social context of treatment may have as much or more of an impact on clients than does the type or content of treatment (Najavits \& Weiss, 1994). From a review of relevant empirical studies, we have formulated some principles about how the treatment alliance and relationships with family and peers are associated with effective treatment for substance use disorders.

Broadly speaking, a good therapeutic alliance is the fundamental quality underlying effective treatment. This is a widely replicated finding in psychotherapy research with heterogeneous treatment samples, and also emerges within the more limited realm of clients with substance use disorders. Furthermore, Rogers's (1957) assertion that genuineness, warmth, and positive regard are key ingredients of effective psychosocial treatment appears to be broadly applicable to clients with substance use disorders. Similarly, clients in involving, supportive, and expressive residential treatment programs tend to develop more positive relationships with fellow residents, to report that treatment enhances their self-confidence, and to be more satisfied with and to remain longer in treatment. These clients also tend to experience better outcomes at discharge from the residential phase of treatment and better post-program alcohol- and drug-related outcomes.

A second set of findings in this review centers on family relationships and treatment outcomes. Clients with social systems supportive of treatment are more likely to enter and complete treatment and achieve better outcomes. When family members are constructively engaged in treatment, engagement and outcomes are also likely to be improved.

These findings raise the question of how to best create strong therapeutic alliances and optimize the involvement of family, which, in turn, can help lead to better outcomes. There is a need for a great deal more research on how to develop optimal treatment alliances in interventions aimed at substance use. Although there is sufficient research to establish a set of working principles for treatment of these populations, our specific principles remain in the realm of the "probably" efficacious at this point in the language of the American Psychological Association's Division 12 Task Force. Despite the clear importance of the relationship factors discussed in this chapter, these factors are rarely addressed in research on treatment outcome. Also, in combining the various literatures about different substance use disorders, we sometimes found very little relevant research concerned with a principle in the domain of a specific disorder. The problem we encountered can only be resolved by incorporating measures of relationship variables into treatment outcome research in the substance use and eating disorders.

The evidence suggests that treatment settings and counselors who are goal-directed and are moderately structured establish better therapy alliances and tend to promote positive in-treatment and posttreatment substance use outcomes. Furthermore, a good treatment alliance and a cohesive treatment setting may be necessary conditions for change, but they are not sufficient conditions. We also believe that to motivate clients to improve, therapists also need to set high expectations and specific performance goals, and to maintain a stable level of structure in treatment. Similarly, we expect that residential treatment programs that emphasize self-direction and the development of work and social skills, are relatively clear and wellorganized, and create strong treatment alliances with clients, tend to engage clients in treatment, reduce clients' substance use problems and symptoms, and enhance clients' community living skills and psychosocial functioning. All of these variables require more attention in our research.

To enhance our understanding of the role of the alliance in the treatment of substance use disorders, research needs to attend to several specific issues. Among these are the role of confrontation, potential variations in the importance of the alliance in different treatment modalities, the influence of the alliance when treatment is mandated, the value of the alliance in group treatment, and the function of the alliance in relation to the match between client-therapist gender, age, race, and similarity of life experience.

One issue involves the apparent negative effects of confrontation, which literally means bringing clients "face to face" with the nature of their problems. Therapists often need to confront clients with addictive disorders by developing and reflecting discrepancies between clients' behaviors and their stated values or goals. Thus, as Miller and 
Rollnick (2002) point out, confrontation often is a goal of treatment; however, it should not be a style of interaction. More information is needed to educate therapists about how they can appropriately confront their clients in a way that helps strengthen the therapeutic alliance.

Two studies of cocaine-dependent clients have noted that, in supportive-expressive therapy, individual drug counseling, and clinical management, a stronger alliance predicts treatment retention-but in cognitive treatment there is no association between the alliance and retention (Carroll, Nich, \& Rounsaville, 1997) or perhaps even a negative relationship (Barber, Luborsky, et al., 2001). The highly directive version of cognitive treatment often employed to treat cocaine dependency may enable clients who develop a strong alliance to increase their self-efficacy and leave treatment more quickly. Alternatively, this modality may weaken the alliance and extend the course of treatment. In any case, more information is needed about the potential differential role of the alliance in diverse treatment modalities.

When treatment is judicially mandated, extrinsic forces that affect clients' motivation and behavior may produce an illusory alliance. For example, among boys with conduct disorders, those who had a positive working alliance at three months were more likely to improve and less likely to be recidivists in the year following placement. However, on average, boys who developed an alliance as early as the third or fourth week of treatment subsequently showed less progress (Florsheim, Shotorbani, Guest-Warnick, Barratt, \& Hwang, 2000). These youth, who may have wanted to "look good" early on and thus developed a "false alliance," failed to progress as staff began to set more limits and expected higher levels of investment in treatment. Because a growing number of clients with substance use disorders are judicially mandated for treatment, we need to determine the influence of situational demands on the measurement and predictive validity of the therapeutic alliance and Rogerian interpersonal attitudes.

Although the majority of treatment for substance use disorders is conducted in a group format, we did not find any empirical studies that specifically examined the therapeutic alliance in this modality. The therapist's warmth, empathy, and genuineness, as well as interpersonal skill and ability to mediate and resolve conflict, are likely to influence group cohesion, treatment retention, and longer term outcome. However, the members' influence on each other may reduce the importance of the leader. More information is needed about the unique characteristics and impact of the alliance in group treatment contexts.

Perhaps the most profitable area for further research lies in examining matches of therapist, therapy, and client. Very little is currently known about the potential differential impact of therapist-client concordance on gender, ethnicity, age, or experiences on alliance in the treatment of substance use disorders. One fruitful area for investigation concerns whether recovering counselors establish a better treatment alliance, and, if so, whether the specific change mechanism is that "recovery status" signifies concordant life experiences between counselor and client. More broadly, studies are needed to examine the role of different aspects of counselor-client concordance in the formation of the treatment alliance. Furthermore, the existent research suggests that the matching of client, therapist, and treatment will have greatest impact when the matching is focused on more complex treatment related characteristics, such as increasing or decreasing family involvement in treatment in relation to the quality of family life, rather than in simple matching by demographic characteristics.

Further investigation is also needed to help unpack the various aspects of the relationship between client and therapist in the treatment of substance use disorders. Broad generalizations of the therapeutic alliance predominate in the existent research connecting process and outcome, while the nuances of different aspects of the therapeutic relationship articulated in the report by the Division 29 Task Force of the American Psychological Association (Norcross, 2002a) (e.g., other relational variables or the differences between tasks, goals, and bonds in the alliance) have yet to receive much attention in this substantive area.

Family and peer support of treatment appears to have special relevance for clients with substance use disorders. The impressive body of work showing the importance of social support in client outcomes naturally suggests developing better methods for achieving such support, both broadly for 
life functioning and specifically in relation to the treatment. Often, in these treatments, the therapy alliance emerges first with family and/or peers and only later is built with the client with the disorder. The impact of family on treatment is clear; these effects are even more pronounced in treatment studies of adolescent substance use disorders that are beyond the domain of this review of adult treatment.

We need much more research illuminating the most efficacious means for deciding when family and/or peers should be part of treatment (and when they should not) and how best to involve them. Beneficial patterns of involvement by family and friends may also vary with clients' individual personality styles.

Research must also specifically focus on the level of family involvement that is most useful at the various "stages of change" (Prochaska \& DiClemente, 1999). Perhaps different methods for building family support and involving family and friends in treatment will prove optimal given the very different patterns for clients, in the precontemplation stage (when problems are not identified by the client but may be by others), the contemplation stage (when problems are identified by the client but he or she is not yet ready to act), the action stage (when the client is actively seeking to alter the problem behavior), and the maintenance stage (when the problem behavior has been changed, but the change must be maintained over time).

Another issue is how much the therapist shapes the alliance and how much it is shaped by the client's characteristics at entry to treatment. In general, among clients with substance use disorders, demographic characteristics and the severity of substance use symptoms emerge as only minimally related to the strength of the alliance (Barber et al., 1999; De Weert-Van Oene et al., 1999; Simpson, Joe, Rowan-Szal, \& Greener, 1995). However, several studies imply that clients who experience more distress, are strongly motivated for treatment, and regularly attend early treatment sessions, establish a stronger treatment alliance (Barber et al., 1999; Connors et al., 2000; Simpson, Joe, Rowan-Szal, \& Greener, 1995). These findings highlight the need for more research into how the interaction of client and therapist characteristics shapes the development of the treatment alliance, and how this process is affected by the therapist's level of directedness and structure and the content of treatment.

In terms of methodology, there is a need for better instrumentation to assess the quality of alliances between extended social support networks and therapists and/or treatment programs, because in the treatment of substance use disorders the therapeutic alliance often expands to include family members, friends, and co-workers. Improvement in the construct and content validity of measures designed to tap the therapeutic alliance, as well as identifying reasons for variations in measurement methods (i.e., client versus therapist self-report versus observer ratings) and the predictive validity of these different perspectives are also fruitful areas for study. In addition, newer analytic techniques, such as hierarchical linear modeling, may enable us to examine these phenomena in a more ecologically valid way (Hser, 1995). As the nature of the therapeutic process becomes more apparent, new concepts and measurement procedures may help us place the alliance in context with other common aspects of treatment, and, more broadly, with other aspects of clients' life experiences that influence the process of recovery.

To emphasize our most important suggestion for further research, relationship variables should be included as an integral part of research on the outcome of treatment for substance use and eating disorders. We hope that with such research, a subsequent review of this area will be able to confirm and expand the principles stated here, and to elaborate additional principles concerned with interactions between clients, therapists, and therapies that can inform us about how best to achieve optimal alliances and involve family in treatment.

\section{SUMMARY}

Studies that have focused on treatment for the substance use and eating disorders have primarily focused on the impact of treatments on outcomes, and only occasionally have considered the importance of relationship factors to outcome. Nonetheless, a considerable literature has identified the powerful role of the therapeutic alliance in treatment-in helping clients enter treatment, remain in treatment longer, to be confident and explore 
problems, to experience less distress, and to produce better outcomes. Likewise, treatment programs are more likely to engage clients more successfully and achieve better in-treatment and after-treatment outcomes when better alliances are created with clients. Relationships with family and friends also appear to have strong effects on engagement, program completion, and outcomes among individuals with substance use and eating disorders. These effects are manifested broadly in the impact of social support on outcome, and, more specifically, in the important roles family and friends can play in supporting treatment; helping to build the alliance between the client, therapist, and treatment program; and becoming involved directly in the treatment process.

ACKNOWLEDGMENTS Preparation of this manuscript was supported by the Department of Veterans Affairs Health Services Research and Development Service research funds and by NIAAA Grant AA12718. The opinions expressed in the manuscript are those of the authors and do not necessarily represent the views of the Department of Veterans Affairs.

\section{References}

Alexander, L. B., \& Luborsky, L T. (1986). The Penn Helping Alliance Scales. In L. S. P. Greenberg \& W. M. Pinsof (Eds.), The psychotherapeutic process: A research handbook (pp. 325-366). New York: Guilford.

American Psychiatric Association. (1994). Diagnostic and statistical manual of mental disorders (4th ed., rev.). Washington, DC: American Psychiatric Association.

Barber, J. G. (1995). Working with resistant drug abusers. Social Work, 40(1), 17-23.

Barber, J. L., Crits-Christoph, P., Thase, M. E., Weiss, R., Frank, A., Onken, L., \& Gallop, R. (1999). Therapeutic alliance as a predictor of outcome in treatment of cocaine dependence. Psychotherapy Research, 9, 54-73.

Barber, J. P., Luborsky, L., Gallop, R., CritsChristoph, P., Frank, A., Weiss, R. D., Thase, M. E., Connolly, M. B., Gladis, M., Foltz, C., \& Siqueland, L. (2001). Therapeutic alliance as a predictor of outcome and retention in the $\mathrm{Na}$ tional Institute on Drug Abuse Collaborative
Cocaine Treatment Study. Journal of Consulting \& Clinical Psychology, 69, 119-124.

Barber, J. S., Halperin, G., \& Connolly, M. B. (2001). Supportive techniques: Are they found in different therapies? Journal of Psychotherapy Practice and Research, 10, 165-172.

Barrett-Lennard, G. T. (1962). Dimensions of the client's experience with the therapist associated with personality change. Genetic Psychology Monographs, 76, No. 43.

Belding, M. A., Iguchi, M. Y., Morral, A. R., \& McLellan, A. T. (1997). Assessing the helping alliance and its impact in the treatment of opiate dependence. Drug Alcohol Depend, 48, 5159.

Bohart, A. C., Elliott, R., Greenberg, L. S., \& Watson, J. C. (2002). Empathy. In J. C. Norcross (Ed.), Psychotherapy relationships that work: Therapist contributions and responsiveness to patients (pp. 89-108). New York: Oxford University Press.

Booth, B. M., Russell, D. W., Soucek, S., \& Laughlin, P. R. (1992). Social support and outcome of alcoholism treatment: An exploratory analysis. American Journal of Drug \& Alcohol Abuse, 18(1), 87-101.

Breteler, M. H. M., Van Den Hurk, A. A., Schippers, G. M., \& Meerkerk, G. J. (1996). Enrollment in a drug-free detention program: The prediction of successful behavior change of drug-using inmates. Addictive Behaviors, 21(5), 665-669.

Broome, K. M., Simpson, D. D., \& Joe, G. W. (1999). Client and program attributes related to treatment process indicators in DATOS. Drug and Alcohol Dependence, 57, 127-135.

Burlingame, G. M., Fuhriman, A., \& Johnson, J. E. (2002). Cohesion in group psychotherapy. In J. C. Norcross (Ed.), Psychotherapy relationships that work: Therapist contributions and responsiveness to patients (pp. 71-88). New York: Oxford University Press.

Carroll, K., Nich, C., \& Rounsaville, B. (1997). Contribution of the therapeutic alliance to outcome in active versus control psychotherapies. Journal of Consulting and Clinical Psychology, 65, 510-514.

Chafetz, M., Blane, H., Abram, H., Golner, J., Lacy, E., McCourt, W., Clark, E., \& Meyers, W. (1962). Establishing treatment relations with alcoholics. Journal of Nervous and Mental Disease, 134, 395-409.

Chambless, D. L., \& Hollon, S. D. (1998). Defining empirically supported therapies. Journal 
of Consulting and Clinical Psychology, 66, 718.

Claiborn, C. D., Goodyear, R. K., \& Horner, P. A. (2002). Feedback. In J. C. Norcross (Ed.), Psychotherapy relationships that work: Therapist contributions and responsiveness to patients (pp. 217-234). New York: Oxford University Press.

Collins, R. L., Emont, S. L., Zywiak, W. H. (1990). Social influence processes in smoking cessation: Postquitting predictors of long-term outcome. Journal of Substance Abuse, 2(4), 389-403.

Connors, G. C., DiClemente, C. C., Longabaugh, R., Donovan, D. M. (1997). The therapeutic alliance and its relationship to alcohol treatment participation and outcome. Journal of Consulting and Clinical Psychology, 69, 588598.

Connors, G. D., Dermen, K. H., Kadden, R., Carroll, K. M., \& Fronte, M. R. (2000). Predicting the therapeutic alliance in alcoholism treatment. Journal of Studies on Alcohol, 61, 139156.

Crape, B. L., Latkin, C. A., Laris, A. S., Knowlton, A. R. (2002). The effects of sponsorship in a 12-step treatment of injection drug users. Drug and Alcohol Dependence, 65(3), 291-301.

Crits-Christoph, P., \& Gibbons, M. B. C. (2002). Relational interpretations. In J. C. Norcross (Ed.), Psychotherapy relationships that work: Therapist contributions and responsiveness to patients (pp. 285-300). New York: Oxford University Press.

Curry, S., Thompson, B., Sexton, M., \& Omenn, G. S. (1989). Psychosocial predictors of outcome in a worksite smoking cessation program. American Journal of Preventive Medicine, 5(1), 2-7.

Dakof, G. A., Quille, T. J., Tejeda, M. J., Alberga, L. R., Bandstra, E., \& Szapocznik, J. (in press). Enrolling and retaining cocaine abusing mothers into drug abuse treatment. Journal of Consulting and Clinical Psychology.

De Leon, G. (Ed.). (1997). Community as method: Therapeutic communities for special populations and special settings. Westport, CT: Praeger.

De Weert-Van Oene, G. D., Jorg, F., \& Schrijvers, G. (1999). The Helping Alliance Questionnaire: Psychometric properties in clients with substance dependence. Substance Use \& Misuse, 34, 1549-1569.

Donohue, B., Azrin, N., Lawson, H., Friedlander, J., Teicher, G., \& Rindsberg, J. (1998). Improving initial session attendance of substance abusing and conduct disordered adolescents: A controlled study. Journal of Child and Adolescent Substance Abuse, 8(1), 1-13.

Edwards, M., \& Steinglass, P. (1995). Family therapy outcomes for alcoholism. Journal of Marital and Family Therapy, 10, 475-509.

Emrick, C. D., Tonigan, J. S., Montgomery, H., \& Little, L. (1993). Affiliation processes in and treatment outcomes of Alcoholics Anonymous: A meta-analysis of the literature. In B. S. McCrady \& W. R. Miller (Eds.), Research on Alcoholics Anonymous: Opportunities and alternatives (pp. 41-76). Piscataway, NJ: Rutgers University, Center of Alcohol Studies.

Fals-Stewart, W., \& Birchler, G. R. (1998). Marital interactions of drug-abusing patients and their partners: Comparisons with distressed couples and relationship to drug-using behavior. Psychology of Addictive Behaviors, 12(1), 2838.

Fals-Stewart, W., Birchler, G. R., \& O'Farrell, T. J. (1996). Behavioral couples therapy for male substance-abusing patients: Effects on relationship adjustment and drug-using behavior. Journal of Consulting and Clinical Psychology, 64(5), 959-972.

Fals-Stewart, W., O'Farrell, T. J., Feehan, M., Birchler, G. R., Tiller, S., \& McFarlin, S. K. (2000). Behavioral couples therapy versus individual-based treatment for male substanceabusing patients: An evaluation of significant individual change and comparison of improvement rates. Journal of Substance Abuse Treatment, 18, 249-254.

Farber, B. A., \& Lane, J. S. (2002). Positive regard. In J. C. Norcross (Ed.), Psychotherapy relationships that work: Therapist contributions and responsiveness to patients (pp. 175-194). New York: Oxford University Press.

Fenton, L. C., Nich, C., Frankforter, T., \& Carroll, K. (2001). Perspective is everything: The predictive validity of six working alliance instruments. Journal of Psychotherapy Practice and Research, 10, 262-268.

Finney, J., \& Moos, R. (1992). The long-term course of treated alcoholism: II. Predictors and correlates of 10-year functioning and mortality. Journal of Studies on Alcohol, 53, 142-153.

Florsheim, P., Shotorbani, S., Guest-Warnick, G., Barratt, T., \& Hwang, W. C. (2000). Role of the working alliance in the treatment of delinquent boys in community-based programs. Journal of Clinical Child Psychology, 29, 94-107.

Freud, S. (1912). The dynamics of transference. In 
J. Strachey (Ed.), The standard edition of the complete psychological works of Sigmund Freud (pp. 99-108). London: Hogarth Press.

Galanter, M. (1993). Network therapy for substance abuse: A clinical trial. Psychotherapy, 30(2), 251-258.

Gallop, R., Kennedy, S. H., \& Stern, D. (1994). Therapeutic alliance on an inpatient unit for eating disorders. International Journal of Eating Disorders, 16(4), 405-410.

Gaston, L. M., \& Marmar, C. R. (1994). The California Psychotherapy Alliance Scales. In A. O. Horvath \& L. S. Greenberg (Ed.), The working alliance: Theory, research, and practice (pp. 85108). New York: Wiley.

Gelso, C. J., \& Hayes, J. A. (2002). The management of countertransference. In J. C. Norcross (Ed.), Psychotherapy relationships that work: Therapist contributions and responsiveness to patients (pp. 267-284). New York: Oxford University Press.

Gerstley, L., McLellan, A. T., Alterman, A. I., Woody, G. E., Luborsky, L., \& Prout, M. (1989). Ability to form an alliance with the therapist: A possible marker of prognosis for clients with antisocial personality disorder. American Journal of Psychiatry, 146, 508-512.

Gordon, A. J., \& Zrull, M. (1991). Social networks and recovery: One year after inpatient treatment. Journal of Substance Abuse Treatment, 8(3), 143-152.

Greenson, R. (1965). The working alliance and the transference neurosis. Psychoanalytic Quarterly, 34, 155-179.

Gruder, C. L., Mermelstein, R. J., Kirkendol, S., Hedeker, D., et al. (1993). Effects of social support and relapse prevention training as adjuncts to a televised smoking-cessation intervention. Journal of Consulting \& Clinical Psychology, 61(1), 113-120.

Hanson, B., Issacsson, S. O., Janzon, L., \& Liddle, S. E. (1990). Social support and quitting smoking for good. Is there an association? Results from the population study "Men Born in 1914," Malmo, Sweden. Addictive Behaviors, 15, 221233.

Hartley, S. W., \& Strupp, H. H. (1983). The therapeutic alliance: Its relationship to outcome in brief psychotherapy. In J. Masling (Ed.), Empirical studies of psychoanalytic theories (pp. 137). Hillsdale, NJ: Analytic Press.

Hatcher, R. L., \& Barends, A. W. (1996). Clients' view of the alliance in psychotherapy: Exploratory factor analysis of three alliance measures.
Journal of Consulting \& Clinical Psychology, 64, 1326-1336.

Henggeler, S. W., Pickrel, S. G., Brondino, M. J., \& Crouch, J. L. (1996). Eliminating (almost) treatment dropout of substance abusing or dependent delinquents through home-based multisystemic therapy. American Journal of Psychiatry, 153, 427-428.

Hill, C. E., \& Knox, S. (2002). Self-disclosure. In J. C. Norcross (Ed.), Psychotherapy relationships that work: Therapist contributions and responsiveness to patients (pp. 255-266). New York: Oxford University Press.

Horvath, A. O., \& Bedi, R. P. (2002). The alliance. In J. C. Norcross (Ed.), Psychotherapy relationships that work: Therapist contributions and responsiveness to patients (pp. 37-70). New York: Oxford University Press.

Horvath, A. O., \& Greenberg, L. S. (1989). Development and validation of the Working Alliance Inventory. Journal of Counseling Psychology, 36, 223-233.

Horvath, A., \& Symonds, D. (1991): Relation between working alliance and outcome in psychotherapy: A meta analysis. Journal of Consulting and Clinical Psychology, 59(2), 139-149.

Hser, Y. (1995). Drug treatment counselor practices and effectiveness: An examination of the literature and relevant issues in a multilevel framework. Evaluation Review, 19, 389-408.

Hyams, G., Cartwright, A., \& Sprately, T. (1996). Engagement in alcohol treatment: The client's experience of, and satisfaction with, the assessment interview. Addiction Research, 4(2), 105123.

Joe, G. W., Simpson, D. D., Dansereau, D. F., \& Rowan-Szal, G. A. (2001). Relationships between counseling rapport and drug abuse treatment outcomes. Psychiatric Services, 52, 1223 1229.

Joe, G. W., Simpson, D. D., Greener, J. M., \& Rowan-Szal, G. A. (1999). Integrative modeling of client engagement and outcomes during the first 6 months of methadone treatment. $A d$ dictive Behavior, 24, 649-659.

Jones, M. (1953). The therapeutic community. New York: Basic Books.

Kelley, M. L., \& Fals-Stewart, W. (2002). Couples versus individual-based therapy for alcoholism and drug abuse: Effects on children's psychosocial functioning. Journal of Consulting and Clinical Psychology, 70, 417-427.

Klein, M. H., Kolden, G. G., Michels, J. L., \& Chisholm-Stockard, S. (2002). In J. C. Nor- 
cross (Ed.), Psychotherapy relationships that work: Therapist contributions and responsiveness to patients (pp. 195-216). New York: Oxford University Press.

Lemke, S., \& Moos, R. (2002). Prognoses of older clients in mixed-age alcoholism treatment programs. Journal of Substance Abuse Treatment, 22, 33-43.

Lichtenstein, E., Glasgow, R. E., \& Abrams, D. B. (1986). Social support in smoking cessation: In search of effective interventions. Behavior Therapy, 17(5), 607-619.

Liddle, H. A., \& Dakof, G. (1995). Family-based treatment for adolescent drug use: State of the science. In E. Rahdert \& D. Czechowicz (Eds.), Adolescent drug abuse: Clinical assessment and therapeutic interventions (pp. 218-254) (NIDA Research Monograph No. 156, NIH Publication No. 953908). Rockville, MD: National Institute on Drug Abuse.

Liepman, M. R., Nirenberg, T. D., \& Begin, A. M. (1989). Evaluation of a program designed to help family and significant others to motivate resistant alcoholics. American Journal of Drug and Alcohol Abuse, 15, 209-221.'

Linn, M. (1978). Attrition of older alcoholics from treatment. Addictive Diseases, 3, 437-447.

Linn, M., Shane, R., Webb, N., \& Pratt, T. (1979). Cultural factors and attrition in drug abuse treatment. International Journal of the Addictions, 14, 259-280.

Long, C. W., Williams, M., Midgley, M., \& Hollin, C. R. (2000). Within program factors as predictors of drinking outcome following cognitive-behavioral treatment. Addictive Behaviors, 25, 573-578.

Longabaugh, R., Beattie, M., Noel, N., Stout, R. \& Malloy, P. (1993). The effect of social investment on treatment outcome. Journal of Studies on Alcohol, 54, 465-478.

Longabaugh, R., Wirtz, P. W., Beattie, M. C., Noel, N., \& Stout, R. (1995). Matching treatment focus to patient social investment and support: 18-month follow-up results. Journal of Consulting and Clinical Psychology, 63(2), 296-307.

Luborsky, L., Barber, J. P., Siqueland, L., \& Johnson, S. (1996). The revised Helping Alliance questionnaire (HAq-II): Psychometric properties. Journal of Psychotherapy Practice \& Research, 5(3), 260-271.

Luborsky, L., Crits-Christoph, P., McLellan, A. T., Woody, G., Piper, W., Liberman, B., Imber, S., \& Pilkonis, P. (1986). Do therapists vary much in their success? Findings from four outcome studies. American Journal of Orthopsychiatry, 5, 501-512.

Luborsky, L. R., Diguer, L., Andrusyna, T. P., Berman, J. S., Levitt, J. T., Seligman, D. A., \& Krause, E. D. (2002). The dodo bird verdict is alive and well-mostly. Clinical Psychology: Science \& Practice, 9, 2-12.

Luborsky, L., McLellan, T., Woody, G., O'Brien, C., \& Auerbach, A. (1985). Therapist success and its determinants. Archives of General Psychiatry, 42, 602-611.

Machell, D. F. (1987). Fellowship as an important factor in alcoholism residential treatment. Journal of Alcohol and Drug Education, 32(2), 5658.

Marmar, C. R., Weiss, D. S., \& Gaston, L. (1989). Toward the validation of the California Therapeutic Alliance Rating System. Psychological Assessment, 1(1), 46-52.

Martin, D., Garske, J., \& Davis, K. (2000). Relation of the therapeutic alliance with outcome and other variables: A meta-analytic review. Journal of Consulting and Clinical Psychology, 68(3), 438-450.

McCrady, B. S., Epstein, E. E., \& Hirsch, L. S. (1999). Maintaining change after conjoint behavioral alcohol treatment for men: Outcomes at six months. Addiction, 94, 1381-1396.

McCrady, B. S., Moreau, J., Paolino, T. J., \& Longabaugh, R. (1982). Joint hospitalization and couples therapy for alcoholism: A four year follow-up. Journal of Studies on Alcohol, 43, 1244-1250.

McCrady, B. S., Noel, N. E., Abrams, D. B., Stout, R. L., Nelson, H. F., \& Hay, W. N. (1986). Comparative effectiveness of three types of spouse involvement in outpatient behavioral alcoholism treatment. Journal of Studies on Alcohol, 47, 459-467.

McCrady, B. S., Paolino, T. J., Jr., Longabaugh, R., \& Rossi, J. (1979). Effects of joint hospital admission and couples treatment for hospitalized alcoholics: A pilot study. Addictive Behaviors, 4, 155-165.

McLellan, A. T., Alterman, A. I., Metzger, D. S., Grissom, G. R., Woody, G. E., Luborsky, L., \& O'Brien, C. P. (1994). Similarity of outcome predictors across opiate, cocaine, and alcohol treatments: Role of treatment services. Journal of Consulting and Clinical Psychology, 62, 11411158.

Miller, W. R., Benefield, G., \& Tonigan, J. S. (1993). Enhancing motivation for change in problem drinking: A controlled comparison of two ther- 
apist styles. Journal of Consulting and Clinical Psychology, 61, 455-446.

Miller, W. R., \& Brown, S. A. (1997). Why psychologists should treat alcohol and drug problems. American Psychologist, 52, 1269-1279.

Miller, W. R., Meyers, R. J., \& Tonigan, J. S. (1999). Engaging the unmotivated in treatment for alcohol problems: A comparison of three strategies for intervention through family members. Journal of Consulting and Clinical Psychology, 67(5), 688-697.

Miller, W. R., \& Rollnick, S. (2002). Motivational interviewing: Preparing people for change. New York: Guilford Press.

Milmoe, S., Rosenthal, R., Blane, H., Chafetz, M., \& Wolf, I. (1967). The doctor's voice: Postdictor of successful referral of alcoholic clients. Journal of Abnormal Psychology, 72(1), 78-84.

Moos, R. (1997). Evaluating treatment environments: The quality of psychiatric and substance abuse programs. New Brunswick, NJ: Transaction.

Moos, R., Finney, J., \& Cronkite, R. (1990). Alcoholism treatment: Context, process, and outcome. New York: Oxford University Press.

Moos, R., \& King, M. (1997). Participation in community. residential treatment and substance abuse clients' outcomes at discharge. Journal of Substance Abuse Treatment, 14, 71-80.

Moos, R., \& MacIntosh, S. (1970). Multivariate study of the client-therapist system: A replication and extension. Journal of Consulting and Clinical Psychology, 35, 298-307.

Moos, R., Mehren, B., \& Moos, B. (1978). Evaluation of a Salvation Army alcoholism treatment program. Journal of Studies on Alcohol, 39, 1267-1275.

Morgan, G. D., Ashenberg, Z. S., \& Fisher, E. B. (1988). Abstinence from smoking and the social environment. Journal of Consulting and Clinical Psychology, 56(2), 298-301.

Morgenstern, J., Blanchard, K. A., Morgan, T. J., Labouvie, E., \& Hayaki, J. (2001). Testing the effectiveness of cognitive-behavioral treatment for substance abuse in a community setting: Within treatment and posttreatment findings. Journal of Consulting and Clinical Psychology, 69, 1007-1017.

Moyer, A., Finney, J., \& Swearingen, C. (2002). Methodological characteristics and quality of alcohol treatment outcome studies, 1970-98: An expanded evaluation. Addiction, 97, 253264.

Moyer, A., Finney, J. W., Swearingen, C. E., \& Vergun, P. (2002). Brief interventions for alcohol problems: A meta-analytic review of controlled investigations in treatment-seeking and nontreatment-seeking populations. Addiction, 97, 279-292.

Najavits, L., \& Weiss, R. D. (1994). Variations in therapist effectiveness in the treatment of clients with substance use disorders: An empirical review. Addiction, 89, 679-688.

Nathan, P. E., \& Gorman, J. M. (Eds.). (2002). $A$ guide to treatments that work ( $2 \mathrm{nd}$ ed.). London: Oxford University Press.

Nides, M. A., Rakos, R. F., Gonzales, D., Murray, R. P., et al. (1995). Predictors of initial smoking cessation and relapse through the first 2 years of the Lung Health Study. Journal of Consulting and Clinical Psychology, 63(1), 60-69.

Norcross, J. C. (2002a). Empirically supported therapy relationships: Summary report of the Division 29 Task Force. Psychotherapy, 38, 345497.

Norcross, J. C. (Ed.). (2002b). Psychotherapy relationships that work: Therapist contributions and responsiveness to patients. New York: Oxford University Press.

O'Farrell, T. J., \& Birchler, G. (2001). Alcohol abuse. In D. H. Sprenkle (Ed.), Effectiveness research in marital and family therapy. Alexandria, VA: AAMFT.

O'Farrell, T. J., Choquette, K. A., Cutter, H. S. G., Brown, E. D., \& McCourt, W. F. (1993). Behavioral marital therapy with and without additional couples relapse prevention sessions for alcoholics and their wives. Journal of Studies on Alcohol, 54, 652-666.

O'Farrell, T. J., Cutter, H. S. G., \& Floyd, F. J. (1985). Evaluating behavioral marital therapy for male alcoholics: Effects on marital adjustment and communication from before and after treatment. Behavior Therapy, 16, 147-167.

O'Farrell, T. J., \& Fals-Stewart, W. (2002). Marital and family therapy in the treatment of alcoholism. Paper presented at the AAMFT Research conference, Reno, NV.

O'Farrell, T. J., \& Feehan, M. (1999). Alcoholism treatment and the family: Do family and individual treatments for alcoholic adults have preventive effects for children? Journal of Studies on Alcohol, 13, 125-128.

Ojehagen, A., Bergland, M., \& Hansson, L. (1997). The relationship between helping alliance and outcome in outclient treatment of alcoholics: A comparative study of psychiatric treatment and multimodal behavioural therapy. Alcohol and Alcoholism, 32, 241-249. 
Ossip-Klein; D. J., Vanlandingham, W., Prue, D. M., \& Rychtarik, R. G. (1984). Increasing attendance at alcohol aftercare using calendar prompts and home based contracting. Addictive Behaviors, 9(1), 85-89.

Ouimette, P. C., Ahrens, C., Moos, R., \& Finney, J. (1998). During treatment changes in substance abuse clients with posttraumatic stress disorder: Relationships to specific interventions and program environments. Journal of Substance Abuse Treatment, 15, 555-564.

Patten, C. A., Martin, J. E., Calfas, K. J., Lento, J., \& Wolter, T. D. (2001). Behavioral treatment for smokers with a history of alcoholism: Predictors of successful outcome. Journal of Consulting and Clinical Psychology, 69(5), 796-801.

Perri, M. G., McAdoo, W. G., McAllister, D. A., Lauer, J. B., et al. (1987). Effects of peer support and therapist contact on long-term weight loss. Journal of Consulting and Clinical Psychology, 55(4), 615-617.

Petry, N., \& Bickel, B. (1999). Therapeutic alliance and psychiatric severity as predictors of completion of treatment for opioid dependence. Psychiatric Services, 50, 219-227:

Porzelius, L. K., Houston, C., Smith, M., Arfken, C., et al. (1995). Comparison of a standard behavioral weight loss treatment and a binge eating weight loss treatment. Behavior Therapy, 26(1), 119-134.

Prochaska, J. O., \& DiClemente, C. C. (1999). Comments, criteria and creating better models. In W. R. Miller and N. Heath (Eds.), Treating addictive behaviors (2nd ed.). New York: Plenum Press.

Project MATCH (1997). Matching alcoholism treatments to client heterogeneity: Project MATCH post treatment drinking outcomes. Journal of Studies on Alcohol, 58, 7-29.

Project MATCH (1998). Matching alcoholism treatments to client heterogeneity: Treatment main effects and matching effects on drinking during treatment. Journal of Studies on Alcohol, 59, 631-639.

Rapoport, R. (1960). Community as doctor. London, England: Tavistock.

Raytek, H. M., Epstein, E. E., \& Hirsch, L. S. (1999). Therapeutic alliance and the retention of couples in conjoint alcoholism treatment. Addictive Behaviors, 24, 317-330.

Rogers, C. (1957). The necessary and sufficient conditions of therapeutic personality change. Journal of Consulting and Clinical Psychology, 22, 95-103.
Rowe, C. L., \& Liddle, H. A. (2002). Recent advances in family based treatment for drug abuse. Paper presented at the AAMFT Research Conference, Reno, NV.

Safran, J. D., Muran, J. C., Samstag, L. W., \& Stevens, C. (2002). In J. C. Norcross (Ed.), Psychotherapy relationships that work: Therapist contributions and responsiveness to patients (pp. 235-254). New York: Oxford University Press.

Safran, J. D., \& Wallner, L. K. (1991). The relative predictive validity of two therapeutic alliance measures in cognitive therapy. Psychological Assessment, 3(2), 188-195.

Santisteban, D. A., Szapocznik, J., Perez-Vidal, A., Kurtines, W. M., Murray, E. J., \& LaPerriere, A. (1996). Efficacy of intervention for engaging youth and families into treatment and some variables that may contribute to differential effectiveness. Journal of Family Psychology, 10, 35-44.

Simpson, D., Joe, G. W., Greener, J. M., \& RowanSzal, G. A. (2000). Modeling year 1 outcomes with treatment process and post-treatment social influences. Substance Use and Misuse, 35, 1911-1930.

Simpson, D. D., Joe, G. W., \& Rowan-Szal, G. A. (1997). Drug abuse treatment retention and process effects on follow-up outcomes. Drug and Alcohol Dependence, 47, 227-235.

Simpson, D., Joe, G. W., Rowan-Szal, G., \& Greener, J. (1995). Client engagement and change during drug abuse treatment. Journal of Substance Abuse, 7, 117-134.

Simpson, D. D., Joe, G. W., Rowan-Szal, G. A., \& Greener, J. M. (1997). Drug abuse treatment process components that improve retention. Journal of Substance Abuse Treatment, 14, 565 572.

Sisson, R. W., \& Azrin, H. H. (1986). Familymember involvement to initiate and promote treatment of problem drinkers. Journal of $\mathrm{Be}$ havior Therapy and Experimental Psychiatry, 17, 15-21.

Stanton, M. D., \& Todd, T. C. (1979). Structural therapy with drug addicts. In E. Kaufman \& P Kaufman (Eds.), Family therapy of drug and alcohol abuse (pp. 55-59). New York: Gardner Press.

Szapocznik, J., Perez-Vidal, A., Brickman, A. L., Foote, F. H., Santisteban, D., Hervis, O., \& Kurtines, W. M. (1988). Engaging adolescent drug abusers and their families in treatment: A strategic structural systems approach. Journal of 
Consulting and Clinical Psychology, 56, 552557.

Thomas, E. J., Santa, C. A., Bronson, D., Osterman, D. (1987). Unilateral family therapy with spouses of alcoholics. Journal of Social Service Research, 10, 145-162.

Thomas, E. J., Yoshioka, M., Ager, R., \& Adams, K. B. (1990). Reaching the uncooperative alcohol abuser through a cooperative spouse. Paper presented at the Fifth Congress of the International Society for Bio-Medical Research on Alcoholism, Toronto, June.

Tracey, T. J., \& Kokotovic, A. M. (1989). Factor structure of the Working Alliance Inventory. Psychological Assessment, 1(3), 207-210.

Treasure, J. L., Katzman, M., Schmidt, U., Troop, N., Todd, G., \& de Silva, P. (1999). Engagement and outcome in the treatment of bulimia nervosa: First phase of a sequential design comparing motivation enhancement therapy and cognitive behavioral therapy. Behaviour Research and Therapy, 37(5), 405-418.

Truax, C. B., \& Carkhuff, R. R. (1967). Toward effective counseling and psychotherapy: Training and practice. Chicago: Aldine.

Tuke, S. (1813). Description of the retreat (Republished in 1996). London: Process Books.

Tunis, S. L.; Delucchi, K. L., Schwartz, K., Banys, P., \& Sees, K. L. (1995). The relationship of counselor and peer alliance to drug use and HIV risk behaviors in a six-month methadone detoxification program. Addictive Behavior, 20, 395-405.

Tryon, G. S., \& Winograd, G. (2002). Goal consensus and collaboration. In J. C. Norcross (Ed.), Psychotherapy relationships that work: Therapist contributions and responsiveness to patients (pp. 109-125). New York: Oxford University Press.

Valle, S. K. (1981). Interpersonal functioning of al- coholism counselors and treatment outcome. Journal of Studies on Alcohol, 42, 783-790.

Waldron, H. B., Slesnick, N., Brody, J. L., Turner, C. W., \& Peterson, T. R. (2001). Treatment outcomes for adolescent substance abuse at 4and 7-month assessments. Journal of Consulting and Clinical Psychology, 69(5), 802-813.

Wampold, B. W., Moody, M., Stich, F., Benson, K., \& Ahn, H. (1997). A meta-analysis of outcome studies comparing bona fide psychotherapies: Empirically, "all must have prizes." Psychological Bulletin, 122, 203-215.

Westerberg, V. S. (1998). What predicts success? In W. R. Miller \& N. Heather (Eds.), Treating addictive behaviors (2nd ed.) (pp. 301-315). New York: Plenum Press.

Wilson, G. T., Fairburn, C. C., Agras, W. S., Walsh, T. B., \& Kraemer, H. (2002). Cognitivebehavioral therapy for bulimia nervosa: Time course and mechanisms of change. Journal of Consulting and Clinical Psychology, 70(2), 267274.

Wilson, G. T., Loeb, K. L., Walsh, B. T., Labouvie, E., Petkova, E., Liu, X., \& Waternaux, C. (1999). Psychological versus pharmacological treatments of bulimia nervosa: Predictors and processes of change. Journal of Consulting and Clinical Psychology, 67(4), 451-459.

Winters, J., Fals-Stewart, W., O'Farrell, T. J., Birchler, G. R., Kelley, M. L. (2002). Behavioral couples therapy for female substance-abusing patients: Effects on substance use and relationship adjustment. Journal of Consulting and Clinical Psychology, 70(2), 344-355.

Zywiak, W. H., Longabaugh, R., \& Wirtz, P. W. (2002). Decomposing the relationships between pretreatment social network characteristics and alcohol treatment outcome. Journal of Studies on Alcohol, 63(1), 114-121. 